Arena 



\title{
Mirada desde Europa, una encrucijada de los medios en América Latina y España. Cuando la Anaconda empieza a mudar la piel
}

\author{
Manuel Chaparro Escudero*
}

\section{Resumen}

Pensar, escribir desde Europa, o sobre Europa obliga hoy a hacer la insidiosa observación de si Europa es capaz de mirar otra cosa que no sea así misma y si, además, tiene algo nuevo que decir. La Europa que soñamos, la Europa que sirvió de modelo a las llamadas sociedades democráticas se diluye en el dibujo de una sociedad más económica que social, más especulativa que solidaria. No es una afirmación ni gratuita, ni exagerada. Europa tiene poco que decir porque hace rato que perdió su brújula. Sólo los movimientos ciudadanos surgidos en el último año (entre ellos el 15-M) sugieren un fin de ciclo de una forma de hacer política que se resiste a cambiar. Frente a esta situación América Latina empieza desde hace algunos años a ofrecer regulaciones de medios más comprometidas con los intereses ciudadanos.

Palabras clave: Europa. América Latina. Regulacione de Medios.

\section{Seen from Europe, a crossroads of the media in Latin America and Spain. When Anaconda began to shed its skin \\ Abstract}

As Europeans, thinking and writing about Europe today, we are forced to ask ourselves the painful question of whether Europe is able to look beyond herself or if she has anything new to say. The Europe we all dreamed about, the Europe which became the model for the so called democratic societies, has been diluted down into an economic rather than social reality. As a society built on

\footnotetext{
* Profesor titular y vicedecano de la Facultad de Ciencias de la Comunicación, Posgrado en Comunicación, Universidad de Málaga (UMA), Málaga-España, y profesor de los programas de doctorado en la UMA y en la Universidad del País Vasco. Es también director del programa de doctorado de la UMA en la Universidad de El Salvador. Fundador en 1984 y director de la Asociación de Emisoras Municipales de Andalucía de Radio y Televisión (www.emartv.com), es coordinador de proyectos de cooperación en Medios de Comunicación en Bolivia, Guatemala, El Salvador y Argentina. Doctor en Ciencias de la Información por la Universidad Complutense de Madrid, ha realizado asesorías en cooperación internacional para la AECID en Argentina, Bolivia y Guatemala. Ha publicado libros y numerosos artículos sobre radio y televisión. E-mail: mch@uma.es
} 
speculation rather than solidarity Europe has little to say because somewhere along the way she lost her bearings. Only mass protests triggered by such things as $15 \mathrm{M}$ are capable of ending political cycles which otherwise refuse to change. As a consequence Latin America has begun, over recent years, to create media regulations which are committed to protecting public interests.

Keywords: Europe. Latin America. Media Regulations.

\section{Uma encruzilhada da mídia na América Latina e Espanha vista da Europa. Quando a Anaconda começa a trocar sua pele Resumo}

Pensar, escrever da Europa ou sobre a Europa nos obriga hoje a fazer uma dolorosa observação sobre se a Europa é capaz de olhar outra coisa se não a si mesma, além de ter algo novo a dizer. A Europa que sonhamos, a Europa que serviu de modelo as chamadas sociedades democráticas se diluiu em um desenho de uma sociedade mais econômica que social, mais especulativa que solidária. Essa não é uma afirmação gratuita nem exagerada. A Europa tem pouco a dizer porque há tempos perdeu sua bússola. Até os movimentos sociais surgidos no último ano (incluindo o 15-M) sugerem o fim de um ciclo de uma forma de fazer política que resiste a mudanças. Frente a esta situação, a América Latina começa, já faz alguns anos, a oferecer regulações dos meios de comunicação mais comprometidas com os interesses cidadãos.

Palavras chave: Europa. América Latina. Regulação dos meios de comunicação.

\section{Introducción}

$\mathrm{R}$ eflejar el escenario de los medios en Europa nos conduce a observar como la tecnología digital ha multiplicado el número más bien se han empobrecido y en el caso de España sin que exista una verdadera apuesta por establecer criterios mínimos de calidad e higiene mental, que permitan la construcción y generación de valores. La sacralidad con que se adorna lo banal, lo burdo, lo obsceno, lo demagógico y el insulto fácil; no permite mejorar estas democracias ni la necesidad de que los medios lideren el necesario abordaje de los nuevos imaginarios y perspectivas que requieren estos tiempos de crisis. No es sólo una cuestión de cambiar un modelo económico que todo lo impregna y altera para adaptarlo a sus necesidades es, fundamentalmente, una cuestión existencial, de supervivencia. 
Europa agota su modelo de bienestar a fuerza de esquilmar el planeta y sus ciudadanos son ahora, sobretodo, consumidores, y como tales ejercen de manera mayoritaria sus derechos. Las grandes plazas públicas para manifestarse y festejar son los centros comerciales. Los derechos ciudadanos conquistados en el siglo 18 son hoy los derechos de los consumidores.

En este paisaje el mérito que tiene la nueva Ley de Servicios de Comunicación Audiovisual de Argentina, es ser una Ley con aportes fundamentados en criterios éticos y no morales-económicos. En Europa hubiera sido incapaz de salir adelante, no por no ser necesaria sino porque el poder económico infiltrado espuriamente en el ámbito de los medios de masas, lo habría impedido, de hecho lo están impidiendo. La flexibilización de las normativas de los diferentes países marcadas por la directivas de la UE han definido un antes y un después que ha penalizado la consideración de servicio público del sector audiovisual.

\section{La oligarquización en el audiovisual}

El deterioro de los contenidos y la precarización laboral vienen acompañados de la creciente oligopolización del mercado. La gestión de los medios se han convertido en una actividad mercantil más sin tener en cuenta la importante función social a la que deben responder. Tan pronto se incrementa el número de actores con la excusa de "ampliar el mapa de la pluralidad", como se genera automáticamente un proceso de fusiones y reabsorciones que vienen a dejar las cosas peor que estaban. El "múltiplex" digital de televisión (cuatro programas por canal) concedido a Prisa ha sido vendido a Tele 5, propiedad de Fininvest (Berlusconi), que ha decidido no mantener la programación del canal generalista "La 4" y con el especializado "todo noticias" CNN+. La apuesta de Fininvest para el canal todo noticias ha sido emitir en abierto durante 24 horas el programa "Gran Hermano" y para "La 4" una fusión de contenidos con Tele 5, eliminando en ambos casos una línea editorial informativa más crítica y fundamentada en el debate, aunque siempre bajo un prisma de intereses mercantiles. 
¿Pluralidad?, ¿Calidad? Al nuevo desembarco de Fininvest se une la propiedad por parte de Agostini de otro de los múltiples digitales en el que está como referencia Antena 3. Incluso ante la difícil coyuntura económica por la que atraviesa Prisa se habla de la venta de las emisoras de radio de la Cadena SER, buque insignia del grupo junto al diario El País, también a Berlusconi.

En ausencia de una verdadera política pública esta son las cosas que pasan. La nueva Ley audiovisual española, la Ley General de la Comunicación Audiovisual (Marzo 2010), consolida la autorregulación por parte de los propietarios de las cadenas y la perdida del compromiso en la prestación del servicio público.

Esta ha sido la tónica en España y otros países de la Unión, siendo Italia, Grecia y España los extremos lamentables y Alemania, Gran Bretaña y Francia las excepciones más honrosas (el orden en este ranking no es por azar y marca diferencias sustanciales). La estrategia general marcada por la UE consiste en debilitar los sistemas públicos, privatizar parte de ellos y aumentar el número de operadores privados para luego permitir su fusión.

A partir de este proceso, el interés de los grupos mediáticos, que responden al poder bancario y de los grandes grupos económicos, no es otro que alimentar los imaginarios sociales que les permiten ejercen el control social, justificar lo injustificable y jugar a imponer agendas políticas interesadas y para nada defensoras de los intereses de la ciudadanía. Los nuevos canales privados en manos de la derecha española (Intereconomía o VEO) apuestan en su línea editorial por una única misión: desprestigiar al gobierno favoreciendo las opciones políticas más ultraconservadoras, trasnochadas y franquistas. El objetivo de los canales no es informar, sino condicionar el voto ciudadano empleando estrategias poco edificantes y fundamentadas en la demagogia propagandística de la caverna más rancia. Los medios al servicio de intereses particulares y espurios.

Los hechos no hacen sino evidenciar que la decadencia de las democracias europeas tiene mucho que ver con la liberalización y desregulación del sector audiovisual, proceso que empezó a fines de los 80 con los vientos tatcheriamos soplando en Bruselas y el reaganismo, que apareció para dar una nueva vuelta de tuerca a 
las tesis más especulativas en lo económico y en lo social. Estos argumentos se reforzaron con el desmoronamiento del bloque soviético. Si la Europa del bienestar y la socialdemocracia evidenciaba sus triunfos era por hacer ver la 'barbarie' sostenida desde la URRS. Eliminado el enemigo, el interés por ofrecer un modelo alternativo humanista se fue desmoronando, el mercado había triunfado y las tesis más liberales encontraban campo abierto. El triunfo de Smith sobre Keynes se consolidaba para seguir viendo el mundo con la mirada del siglo 19.

La mercantilización de la información y la comunicación, de las redes de distribución, de las Tecnologías de la Información han provocado el desmantelamiento y empobrecimiento de los modelos públicos. El concepto de Servicio Público ya no es aplicable a los medios privados comerciales, lo que supone una cierta privatización del espacio radioeléctrico y nulo compromiso por los contenidos de utilidad para la ciudadanía. Este extremo de liberalización aplicado en Francia y España no ha sido, sin embargo, respaldado por el campeón del libre mercado, EE.UU.

\section{Poder político, poder mediático, poder ciudadano}

Pero, icómo justificar que en la Europa democrática el poder político, el poder mediático y el poder económico se pongan de acuerdo para evitar una verdadera democratización del espacio audiovisual? El poder político y legislativo están siendo incapaces de poner en su agenda un verdadero compromiso por democratizar el espacio radioeléctrico, ante las presiones chantajistas del poder económico instalado en los grupos mediáticos dominantes. No todos los países reflejan el mismo paisaje, en algunos ya citados; como Alemania, todavía se puede ver un modelo de equilibrios, objetividad y calidad en los canales públicos.

Una mirada al paisaje europeo de los medios audiovisuales deja ver que en ninguna de sus democracias los medios ciudadanos gozan de los privilegios que tienen los medios privados comerciales y los públicos. Los medios privados comerciales son los únicos capacitados, para dictar doctrina y moral, priorizar agendas y exorcizar los males sociales de los que parece que no son victimas 
sus ciudadanos, más bien culpables a los que hay que adoctrinar, contener y convencer.

Las causas que dieron lugar a la Ley Argentina vienen a justificar una acción legítima del ejecutivo y el legislativo. Estas mismas causas existen en Europa, donde los Medios miran con inquietud los progresos que se realizan en América Latina como penalizaciones a la libertad de expresión, sin entender que ésta no tiene ninguna relación con la libertad de empresa y con la apropiación del espacio radioeléctrico.

La OMC ha jugado a favor de esta corriente desregularizadora que provoca un efecto negativo similar al producido sobre la mercantilización y especulación con los alimentos hasta provocar la crisis alimentaria que hoy vive el planeta. El mundo de los tangibles e intangibles tiene aquí fronteras que determinan un denominador común, la necesidad que tenemos de protegernos del economicismo, no de la economía. Las materias primas del sector primario esenciales para la supervivencia son extremadamente sensibles al mercado y tan fundamentales para la población como la materia prima que cuida el intelecto y que exige la protección el derecho a la educación, la cultura, el acceso a los Medios y a una información plural y democrática.

La reforma Argentina, inspirada en la tradición europea, pero también en una constante reivindicación de los movimientos populares latinoamericanos, plantea además una conquista mal definida en Europa, la participación ciudadana en las ondas o como dijo Pasquali (1973): la aspiración a la Comunicación Comunitaria como paradigma de la auténtica comunicación frente a quienes defienden simplemente una Sociedad de Información.

Es evidente que información y comunicación no son la misma cosa. Son conceptos que pueden llegar a ser antagónicos y vienen a definir la unidireccionalidad frente a la bidireccionalidad, lo vertical frente a lo horizontal, la pasividad frente a la actividad. Todo lo opuesto a las tesis del maestro Freire y a la formulación del EMIREC de Jean Cloutier (1975), como acrónimo que reúne en un mismo actor las dos condiciones, la de emisor y receptor. Los Medios de información son necesarios, pero más aún lo son los Medios de Comunicación, garantes de 
la participación, de trabajar la proximidad y fomentar procesos endógenos de apropiación y toma de decisiones. Los Medios comunitarios en su construcción horizontal facilitan el elemento imprescindible dialógico que exige el proceso de la comunicación (Beltrán, 1979).

Los medios ciudadanos, comunitarios o asociativos existen en Europa pero juegan en desventaja con respecto a los medios privados comerciales y los públicos. En líneas generales están sujetos a esa máxima definida en Latinoamérica que los califica como "pobres, pocos y pequeños". Su capacidad de incidencia social es residual, son medios militantes escasamente integrados, en la mayoría de los casos con escasa incidencia popular. En algunos países como España ni siquiera están regulados y la reciente aprobación de la Ley General de la Comunicación Audiovisual, ha seguido dejando pendiente una asignatura que define el estado de salud de una democracia señalando un déficit inadmisible.

Un pequeño resquicio se ha abierto al amparo de una disposición adicional de la Ley de Impulso de la Sociedad de la Información (LISI, 2007). Las televisiones comunitarias que venían emitiendo podran seguir con su labor, no son muchas, apenas una decena. En cuanto a las radios, una propuesta de reglamento elaborado por el gobierno propone reducir su potencia a sólo un vatio de potencia. La ridícula propuesta ha sido contestada por las emisoras, colectivos ciudadanos y la comunidad académica cuyos centros tampoco tendrían acceso al espectro.

La Ley Argentina supera ampliamente cualquier legislación europea. iEs desmedida esta Ley? Eso dicen sus detractores, pero olvidan que satisface un principio constitucional y se apoya en la Declaración Universal de los Derechos Humanos, o iésta tan poco vale? Puede que no la conozcan porque una cosa es informar de la ONU, de sus acuerdos y sus políticas, y otra saber que existe una Declaración Universal que respalda su actuación y esta aceptada por todos los países miembros.

Que la ciudadanía tenga que estar en silencio en una democracia es no sólo perjudicial sino peligroso. Que los medios definan e interpreten el sentir, la inquietud y el deseo de los ciudadanos en función de intereses propios ocultos es desestabilizador. 
La información es hoy un valor económico, los medios comerciales sólo tienen como objetivo la producción de beneficios económicos y la eliminación de competencia. La información y sus medios de distribución deberían estar fuera de esta cadena para preservar los valores de la democracia.

Tan ajenos se está al sentir de los ciudadanos que los medios masivos y los propios gobiernos se sorprenden ahora de lo ocurrido en el norte de África. Egipto, Túnez, Baherin, Yemen, Libia, Argelia, Marruecos... Regímenes dictatoriales sin libertad de prensa, usaban y usan los medios para dibujar una realidad que no refleja el sentir social. Los Medios interpretan la realidad acomodándola a sus intereses, generando realidades virtuales, invisibilizando problemas reales. La realidad termina por imponer su verdad pero a costa de una degradación dolorosamente innecesaria. El periodismo y los medios deben cambiar y no se hará sin un pacto que asegure una regulación que los ponga al servicio de la ciudadanía (CHAPARRO, 2010).

Este paisaje no corresponde solamente a países donde la democracia es débil, aparente o inexistente. La ausencia de regulaciones justas se da también en los países que hasta ahora se creían modelos o representaban el paradigma de la democracia. Nuestras democracias se han convertido en mediocracias, un poder al margen de la ciudadanía y en contra de sus intereses que pone en peligro todo el sistema.

\section{Regulación y financiación}

El problema no es nuevo. El informe de la Comisión MacBride ya denunció no sólo los desequilibrios de flujos existentes, sino la ausencia de un acceso ciudadano que facilitara una verdadera construcción democrática desde la participación real en la toma de decisiones. Antes del informe del Premio Nobel, América Latina ya había reivindicado en la Conferencia Intergubernamental sobre Políticas de Comunicación de San José de Costa Rica (1976) la necesidad de cambiar el modelo:

El ser humano tiene la necesidad vital de expresarse, debiendo garantizársele por tanto la facultad libre y expontanea de relacionarse dentro de la Comu- 
nidad [...] es un derecho humano el acceso a todos los bienes de la cultura y la participación libre y democrática [...] Los estados tienen obligaciones y responsabilidades sociales, económicas y éticas en todo cuanto se refiere al estímulo, apoyo, promoción, difusión de bienes de la comunidad, para el desarrollo integral, individual y colectivo $[\ldots]$ - es necesario - establecer planes y programas para el uso extensivo de los medios de comunicación social, dentro de las políticas de desarrollo.

El único problema de esta declaración es su hincapié en el objetivo prioritario y obsesivo por el desarrollo como respuesta a los problemas, sin tener en cuenta que ello suponía la aceptación de una dependencia fatal de sus economías y el crecimiento de la brecha de la desigualdad.

En los últimos 30 años los intentos de reforma han sido tan pobres que el desequilibrio a fuerza de no legislar ha empeorado. Los únicos avances se han producido de manera significativa en América Latina, sobretodo en el reconocimiento de los medios comunitarios. Las regulaciones de Colombia y Venezuela, son relevantes. Las propuestas que se trabajan en Uruguay, Ecuador y Bolivia son ilusionantes, aunque los últimos anuncios del gobierno de Evo hacen dudar sobre una verdadera voluntad de vencer la presión de los medios privados comerciales. En todo caso permite a estos medios una posibilidad de incidencia social imposible en Europa que parece confiar la capacidad de intervención ciudadana cada vez más a las llamadas "redes sociales", aunque el ciberactivismo pueda ser una opción de respuesta no deja de ser un medio bajo el dominio de determinadas élites y que interactúa principalmente entre líderes de opinión, sin ser una herramienta verdaderamente popular y de acción permanente. Internet como dice Richieri ${ }^{1}$ supone también una cierta atomización, una fragmentación y dispersión de las expresiones populares.

En este marco de transformaciones el caso de Perú es llamativo. La propuesta popular de Ley de Medios trabajada en un largo proceso de debate llevado a todas las calles de Perú generando un amplio consenso, resultó finalmente modificada por los diputados durante su tramitación, un mal ejemplo de cómo a veces los cargos electos

\footnotetext{
${ }^{1}$ Intervención en Foro Internacional Comunicación, Desarrollo y Cambio Social. Sevilla, 2008.
} 
escuchan las demandas de sus representados. En Ciudadan@s de a de veras, Rosa María Alfaro (2002) relata el amplio proceso popular seguido para sacar adelante la propuesta de vigilancia de la gestión pública, especialmente de los medios y la clase política. El evidente divorcio existente entre la ciudadanía y los poderes representados por el Estado y los medios, estuvo detrás de estas iniciativas que tratan de extenderse a todo el continente.

En el caso argentino lo más interesante es el logro de haber realizado una reforma integral que afecta al conjunto del sistema y da oportunidad a los modelos comunitarios y ciudadanos. Una reforma valiente, dialogada y consensuada con los movimientos sociales. Quedan algunos aspectos mejorables, pero tal vez sea necesario dar los pasos en el momento adecuado. Se debe trabajar en el consenso político para consolidar la autonomía e independencia de la autoridad reguladora, en establecer cauces de financiación que hagan posible la pervivencia de los medios ciudadanos y en lograr que como bien dice Rosa María Alfaro (2006) los medios públicos sean de los públicos.

No son, sin embargo, cuestiones sobre las que convenga dilatar la decisión. La concesión de explotación del espacio radioeléctrico para fines de lucro (radios y televisiones comerciales) debe generar un beneficio que repercuta sobre los medios asociativos. Un impuesto especial contribuiría a la sostenibilidad de los medios ciudadanos en base a propuestas planificadas con objetivos sociales. Los medios comunitarios son medios de proximidad, fundamentales en los procesos de mediación y articulación social. Desde esta necesidad es imprescindible su protección y garantía de funcionamiento.

El recurso a la autofinanciación publicitaria es un derecho pero no una garantía ni de sostenibiliad ni de independencia y la recogida, colecta de fondos o aportaciones voluntarias, aún siendo meritorias e importantes por su valor participativo, reducen, cuando se convierten en la única opción, a la categoría de indigentes mediáticos a las emisoras.

Francia ofrece un ejemplo en este sentido. El Ministerio de Cultura francés, administra el llamado Fonds de Soutien a l'expresion Radiophonique (FSER). Este fondo distribuye ayudas a los proyec- 
tos de incidencia social que presentan las emisoras de la sociedad civil denominadas: asociativas. Este fondo creado en 1982 con el objetivo de asegurar el servicio de la comunicación social de proximidad de las radios asociativas, se obtiene del cobro de una tasa fiscal sobre la publicidad difundida por la radio y la televisión comercial. El FSER, preve ayudas por un importe máximo de 18.000 euros por año. Estas ayudas pueden ir destinadas a gastos de constitución e instalación, equipamientos, gastos de explotación y a programas de actividades radiofónicas concretas. En 2008, el fondo disponible administrado por la Comisión del Ministerio de Cultura ascenció a 6,2 millones de euros.

La fórmula del cobro de una tasa también se aplica en España para garantizar el funcionamiento de la Comisión del Mercado de las Telecomunicaciones (CMT). Este organismo fue creado en 2003 para hacer la veces de órgano de regulación, pero sus competencias son reducidas interviniendo fundamentalmente como órgano de arbitraje y sancionador: "tiene por objeto el establecimiento y supervisión de las obligaciones específicas que hayan de cumplir los operadores en los mercados de telecomunicaciones y el fomento de la competencia en los mercados de los servicios audiovisuales".

El presupuesto de la CMT en 2010 ascendió a 36,6 millones de euros, aportados por la tasa impuesta a los operadores que prestan servicios de telecomunicaciones por la emisión de certificaciones y administración del espectro. La tasa se establece sobre un porcentaje de la facturación bruta de las empresas fijado en el 0,01\%. Este modelo de financiación es el que se pretende aplicar al futuro Consejo Estatal de Medios Audiovisuales (CEMA) que será responsable de regular los medios audiovisuales a imitación del modelo francés. Sin embargo, la oposición de los grupos multimedias, que defienden la autorregulación, está volviendo a retrasar su puesta en marcha y no se vislumbra en el horizonte una solución a corto plazo. El mercado vuelve a imponer su norma por encima de las decisiones del legislativo. Las dudas del gobierno vienen también marcadas por la situación de crisis económica y la ausencia de apoyo de la derecha política, más interesada en la privatización del sector público y su reducción a lo simbólico. 
Las decisiones de la UE tampoco ayudan y suponen un freno a los planes del gobierno sobre el Ente Público RTVE. En 2009 se tomo la decisión de suprimir la emisión de publicidad a partir de 2010 y financiar el servicio público estatal a través de dos tasas: a las telecos del 0,9\% sobre sus ingresos brutos (187,9 millones de euros) y a las televisiones privadas que emiten en abierto el $3 \%$ $(57,4)$ y $1,5,(13,2)$ si son de pago. Esta decisión dejaba el mercado publicitario a las cadenas privadas, tal como venían reclamando con acusaciones al sector público de competencia desleal por su doble financiación a través de los presupuestos del Estado y la publicidad. La comisaria europea de la Agenda Digital, Neelie Kroes ha denunciado a España y Francia ante el Tribunal de Justicia de Luxemburgo por la imposición de tasas. Bruselas argumenta que este gravamen limita las posibles inversiones de las compañías de telecomunicaciones en la mejora de sus redes y la prestación de servicios. Tanto Francia como España argumentan su autonomía fiscal para la toma de estas decisiones.

La medida a contribuido a la mejora de la calidad de la televisión pública e incluso ha aumentando su liderazgo en audiencias. Las dos principales cadenas privadas de televisión (Tele 5 y Antena 3) han batido a su vez el record de beneficios, pero aprovechando la ola de la crisis han despedido a trabajadores y lejos de reinvertir parte de los mismos el cien por cien se ha repartido entre los accionistas. El argumento de la Comisaria carece de la necesaria solidez.

El fracaso de España en la administración del espacio radioeléctrico, en terminar con los intereses oligopolísticos y cumplir con estándares de calidad, encuentra en Francia un ejemplo de savoir faire que debe ser tenido en cuenta. El Consejo Superior del Audivisual (CSA) es el organismo encargado de la regulación. Cierto es que se trata de una institución cara, la independencia del organismo se paga, pero dentro de las deficiencias y la lucha de intereses en el sector, el CSA es capaz de imponer criterios y asegurar la pluralidad. El CSA es responsable de distribuir las concesiones a las emisoras de radio y televisión y asegurar la pervivencia de las emisoras asociativas aunque en una lucha desigual con los medios públicos y privados comerciales y asegu- 
rar los estándares de calidad en los contenidos. El modelo no es perfecto aunque tenga aspectos claramente rescatables, sobretodo frente a otros países europeos donde la permeabilidad de intereses entre gobiernos y grupos no ha permitido una regulación eficaz y constructiva para la democracia. EL CSA es autónomo del poder político y económico y sus consejeros elegidos por consenso y desde el criterio de la independencia y la profesionalidad más que el de las cuotas políticas, constituye una cierta garantía envidiada en otros países. En Francia, al igual que en Gran Bretaña y Alemania la principal fuente de financiación de la radio y televisión pública es a través del canon por aparato que se complementa con ayudas adicionales de los presupuestos generales.

La ausencia de un verdadero papel de mediación es también causa de la falta de incentivos de participación en la vida democrática. Los Medios en su discurso y apropiación de la opinión desincentivan la participación democrática. El número de votantes se reduce en cada convocatoria electoral. Cansancio, descrédito y ausencia de oportunidades reales de intervención pública es también responsabilidad de los Medios incapaces de proponer agendas que respondan a los intereses de la ciudadanía. No podemos pensar en la domesticación permanente de las audiencias y en que estas como decía Dallas Smhite (1983) se vean reducidas a la condición de "pescaditos en la red" y cuyo peso cotiza en el mercado de la publicidad. El proceso de mercantilización de la información y de globalización elimina la centralidad de los sujetos en los procesos comunicativos (SERVAES, 2002). De ahí la necesidad de repensar los Medios y devolverles su verdadera función.

\section{El papel de los medios}

Una Ley es el primer paso de la gran reforma pendiente que involucra a toda la sociedad, pero son necesarias más iniciativas y establecer amplios consensos sociales para conseguir todos los objetivos. Cambiar este sistema perverso exige modificar el modelo empresarial mediático. Acabar con la concentración de medios pero además con el objetivo de interés economicista que mueve a la persona física o jurídica que ostenta la propiedad de 
la concesión. Es casi imposible pensar en un sistema de medios útil para la ciudadanía sin modificar también la forma y los modos de financiación de los medios. Es una certeza que los Medios se deben al capital que los hace posible. Aún aceptando esta realidad, la lógica democrática exigirá que los intereses comerciales de las empresas de comunicación sean exclusivamente los de la industria editorial. No se puede concebir capital ajeno a estos intereses participando en el accionariado, en la propiedad de los medios. En el ámbito de la comunicación las empresas deben sustentarse con recursos provenientes de la producción editorial.

Cuando se le pregunta a Ramonet sobre la independencia de Le Monde, su primer argumento es que se trata de una empresa editorial y su capital es de ámbito editorial, no es de cementeras, petroleras, bancos, aseguradoras o fondos especuladores. La segunda consideración es que sus ingresos por publicidad no deben superar el 20\% anual de sus presupuestos. Esto significa que sus recursos se obtienen principalmente de la venta editorial. Tal vez no sea una empresa modélica en sus ejercicios económicos, entre otras cosas porque sus asuntos internos se discuten hasta en sus propias páginas, algo impensable en la competencia, pero es seguro que casi nadie discute la excelencia y calidad de su producto, aún no coincidiendo ideológicamente con ella.

El coste de la independencia se mide también en las inserciones publicitarias. Depender exclusivamente o mayoritariamente de estos ingresos condicionan la línea editorial. La diferencia ideológica nada tiene que ver con la venta de información o comportamientos que dañan el enfoque de la noticia.

Mientras las grandes corporaciones manifiesten su interés por estar en el capital de los Medios, éstos no dejaran de ser sospechosos de alimentar y servir a intereses espurios.

Al margen de la necesidad de regular, de encontrar modelos eficaces y respetuosos con los intereses de la ciudadanía existe un problema igualmente trascendente: la redefinición del rol que deben desempeñar hoy los medios. Los medios ejercen un poder que necesita ser regulado, ningún poder debe escapar a la regulación. El control del gobierno por el legislativo y el judicial, el equilibrio de poderes entre los tres, constituye un pilar básico en 
democracia. Los medios juegan un papel esencial pero debe garantizarse que juegen a favor de los intereses de la ciudadanía. Jesús Martín Barbero (1987) advierte que el poder de los medios trata de legitimar ante todo la "omnipresencia mediadora del mercado. Pervirtiendo el sentido de las demandas políticas y culturales [...] se deslegitima cualquier cuestionamiento de un orden social al que solo el mercado y las tecnologías permitirían darse forma”.

Más allá de reconocer que la estructura de medios existente en la mayoría de países no garantiza la democracia sin la existencia de una regulación, se impone otro aspecto crítico de calado que debe ser tenido en cuenta. El imaginario social que construyen los medios se sitúa en las antípodas de su papel de mediadores y defensores de los derechos de la ciudadanía, de generación de un auténtico debate social que vaya más allá de responder a las inquietudes e intereses del mercado. Martín Barbero (2003) ya dijo refiriéndose a Latinoamérica que nuestras gentes pueden con cierta facilidad asimilar las imágenes de la modernización y no pocos de los cambios tecnológicos pero sólo muy lenta y dolorosamente pueden recomponer sus sistemas de valores, de normas éticas y virtudes cívicas.

El actual modelo industrial y la especulación económica, han llevado a nuestras sociedades a una ceguera donde la inmoralidad de un sistema sigue encontrando justificación para reivindicarse en el discurso de los Medios.

Los Medios construyen identidades y promueven valores, que sus proyecciones respondan a los aspiraciones democráticas debe ser el objetivo final de cualquier reforma legislativa.

En el umbral de un nuevo siglo el verdadero debate que debe introducir los cambios necesarios aparece hurtado, la descolonización de imaginarios empieza por la circulación y apropiación de las ideas. La información que circula desdibuja la realidad, la disfraza y produce contradicciones que cortocircuitan la relación con un mundo real y la necesidad ética de responder a los abusos del desgobierno y la insensatez del mercado. Tal vez porque como expresa irónicamente de Regis Debray (1993): "Las historia material de las transmisiones y la historia política de la libertad son inseparables. Dime, democracia, cuáles son tus vectores cardinales, y yo te diré 
dónde están tus valores, tu fuerza pero también tus padecimientos y tus vulnerabilidades. Puesto que en gran medida esos Medios disponen de ti, de ti, insensata que crees disponer de ellos”.

La invisibilización de la realidad es un serio problema que evita debates necesarios. En España uno de cada cuatro niños nace con riesgo de exclusión y pobreza. La bolsa de pobreza ya endémica alcanza los diez millones de personas. En la UE la cifra se eleva por encima de los 90 millones. La banca arruina la economía doméstica pero sigue teniendo beneficios escandalosos. El precio de los alimentos sube para los hogares pero se compra por debajo del precio de coste arruinando a los medianos y pequeños productores. El campo que nos debe dar de comer se siembra para hacer andar autos. Los precios de la vivienda son inalcanzables para los salarios medios y es necesario hipotecar toda una vida de ahorro. La educación atiende necesidades empresariales antes que educativas. Producimos más basura que bienes útiles, somos el único ser vivo del planeta que produce basura inorgánica, no reabsorbible por la naturaleza. La contaminación reduce nuestro hábitat y deteriora gravemente nuestra salud, más de 3.500 productos altamente venenosos son utilizados a diario. Destruimos el hábitat de otros pueblos para mantener el nuestro. No existe una crisis económica, existe una crisis de valores que impide la redistribución de la riqueza. No existe crisis alimentaria, hay alimentos y campos de cultivo suficientes pero se especula con la tierra. Sembramos millones de hectáreas de flores en los países empobrecidos en vez de alimentos para los estómagos. Dedicamos miles de hectáreas de cultivo para de comer a los automóviles y mientras permitimos la dependencia de una alimentación cada vez más cara para la mayoría de las familias. Crisis de valores, crisis en las políticas públicas.

Hemos perdido el concepto de ser nativos de este planeta, ni nos respetamos como raza, ni respetamos los ecosistemas para preservarlos. El discurso del éxito basado exclusivamente en el dinero permanece.

¿Qué queremos entonces comunicar? Una ley se cambia en un día, los hábitos culturales en años, en decenas de años. No sólo es necesario reformar las leyes es necesario reformar los discursos 
y hacerlos acordes a los tiempos, a las soluciones planteadas a problemas actuales. Ese debe ser el compromiso de los Medios.

Los Medios acostumbran en convertir en noticia asuntos de enorme banalidad y en banalizar la información trascendente. El debate real se hurta porque interesa más vender la espectacularidad de la noticia. Son discursos tan contradictorios que no permiten a la ciudadanía hacer esa necesaria construcción de la realidad que nos situaría en la antesala de una opinión crítica y constructiva, implicada en las transformaciones necesarias. En un minuto se puede escuchar una noticia sobre los peligros de la contaminación, nuestra forma de vida perjudicial para el medio ambiente y la necesidad de cambiar hábitos, para pasar a la explotación por Repsol de pozos de petróleo en Alaska "donde no hay peligro porque no es territorio habitado". A la noticia sobre el número de accidentes en carretera y la importancia de reducir la velocidad para contaminar menos y ahorrar combustible, le sigue la 'maravilla' de la velocidad en la Fórmula Uno. De la escasez de energía y los problemas derivados su producción al campeonato nocturno de moto GP en Qatar que necesita una iluminación equivalente a la de 40 estadios de fútbol.

Hablamos de los 4,5 millones de desempleados en España sin expectativas, del buen día de resultados en la bolsa y continuamos con la grosería de la lista Forbes para ver con orgullo que entre los diez primeros puestos aparece un español 31.000 millones (Amancio Ortega, ZARA), y como nos entristece que Botín (Banco de Santander) pase del puesto 582 al 833, con una fortuna de 1.500 millones de dólares. Esquizofrenia informativa.

El discurso de los Medios es responsable de la creación de falsos imaginarios entre ellos la mayor quimera del siglo 20: el desarrollo. Cuando la comunidad pensante se pronuncia de manera generalizada y contundente en contra de una idea especuladora y falaz que ha empobrecido al planeta y no ha distribuido riqueza, una vez más, los Medios, vuelven a ocultar el discurso. Una vez más volvemos a la complicidad en la propiedad de los medios con ese mundo empresarial que defiende un modelo obsoleto, egoista y esquilmador basado en una creencia occidental llamada desarrollo. 


\section{Comunicar los nuevos imaginarios}

Desarrollo es un 'pensamiento' económico que implica acumulación de capital como concepto de crecimiento permanente, sin plantear una distribución de los beneficios y sin considerar los efectos de la sobreexplotación del planeta. Ese modelo es la causa de un crecimiento económico directamente proporcional al crecimiento de la pobreza.

Nunca en la historia de la humanidad tantos pueblos vivieron en el estado de pobreza en el que hoy se encuentran, simplemente porque creyeron en una quimera o se les impuso un modo de vida ajeno que fundamenta la felicidad en la compulsiva capacidad de compra. Aunque fuera ideal, es imposible homologar la huella ecológica de un ciudadano medio de Europa con uno procedente de un país empobrecido, este modelo trasladado a los casi siete mil millones de habitantes haría imposible la vida en el planeta, no sería soportable. Que Occidente y en general las sociedades "desarrolladas" de cualquier país sigan vendiendo la idea del desarrollo no deja de ser una idea ciertamente falaz y de tintes criminales.

Desde el discurso de Truman en 1949, la idea del desarrollo no ha dejado de estar en nuestras cabezas, toda sociedad y cultura no homologable en términos del capitalismo USA, se traduce en pobreza y "subdesarrollo", un reduccionismo peligroso y excluyente que ha causado más de 200 conflictos bélicos en los últimos 50 años. Para las Naciones Unidas de la época el progreso humano sólo podía residir en el desarrollo, entendiendo éste como conocimiento para la explotación de todos los recursos naturales (Escobar, 1996).

¿Es verdaderamente el objetivo del ser humano la explotación de los recursos? La simple idea no sólo deja de producir felicidad, deprime.

El pensamiento crítico ha sido capaz de discutir la oportunidad del desarrollo como modelo económico y también ha propuesto alternativas lógicas que vienen dando a conocer desde los años 70' pensadores como Georgescu-Roegen, Ivan Illich, Rist, Latouche, Esteva, Escobar ... La misma ONU encargó por aquella época a la Fundación Dag Hammarkjöld el informe "Qué 
hacer”, en 1975, que venía a plantear soluciones urgentes, todavía no adoptadas por la comunidad internacional aunque se siga opinando de manera generalizada sobre su conveniencia. Medidas sencillas como acabar con la programada obsolescencia de los productos que adquirimos, reducir el consumo de carne, fabricar viviendas perdurables y potenciar el transporte público. Un discurso dirigido a las sociedades "desarrolladas", esas que habitan en el llamado "Occidente", un espacio que se ubica realmente en los hogares de no más de 1.000 millones de habitantes y con desigualdades entre ellos, porque ante todo es esa la sociedad que debe cambiar para permitir el espacio legítimo del resto de la humanidad. La media de hectáreas que necesita cada habitante del planeta para garantizar su supervivencia en condiciones óptimas es de 1,8. Que un estadounidense necesite para mantener su estandar de vida una media de 9,6 hectáreas por habitante o un europeo 4,5, frente a menos de una hectárea de un africano, da idea de las proporciones del planeta y de la imposiblidad de seguir pidiéndole al resto de la humanidad que intente alcanzar niveles de consumo que jamás logrará. El discurso de los medios reproduce esta falacia cada día. Si las sociedades desarrolladas no empiezan a decrecer será imposible conseguir un modelo de equidad en el planeta. Para vivir bien no es necesario seguir en un crecimiento permanente. El crecimiento no implica progreso, implica explotación intensiva constante de los recursos y los seres que habitan el planeta, incluida la raza humana.

La socialización de nuevos imaginarios alejados de la avaricia y la estupidez de la trampa desarrollista debe acercarnos a una visión que se mueva en torno a tres ejes: la economía, la ecología y la equidad como un fractal de equilibrios que deben ir de la mano (Braungart y McDonougts, 2009). Junto a esta idea la necesidad de reivindicar la proximidad en la agricultura y los procesos industriales constituyen la base de un sistema ecoeficiente y garante de la soberanía. Renunciar a los alimentos viajeros, al capitalismo verde de la agroindustria, a los procesos industriales innecesarios por contaminantes deben ser parte de los objetivos de una información y comunicación que faciliten un nuevo conocimiento y nuevas oportunidades. 
No es que estos discursos estén ausentes en los medios, simplemente están ignorados. Tratados con una vehemencia ridiculizante e infantilizadora, en una minoría tan escasa de canales y en franjas horarias inusuales, que finalmente su impacto se ve muy reducido. icómo conseguir ciudadanía crítica si se hurtan los debates, la información real y no se incide sobre las soluciones que se plantean? Ante una catástrofe nuclear en Japón se abre un debate mediático sobre la necesidad de su uso o no, sin que se dejen ver pueblos autosuficientes en energía (Alemania) que se han desconectado de la red de distribución general, hospitales que funcionan exclusivamente con energía solar, o zoológicos que aprovechando las heces de los herbívoros producen toda la energía que necestian sus instalaciones. Somos capaces de vivir sin una necesidad creada por intereses economicistas y propagada por los medios como verdad segura e incuestionable. Como dice el periodista José Miguel Monzón (Gran Wyoming²), los Medios más que practicar la libertad de expresión practican la libertad de excreción, lástima que este tipo de excreción no sirva ni para encender una bombilla.

La comunicación debe promover como objetivo el empoderamiento de la sociedad civil, su capacidad de respuesta crítica, su participación desde el manejo de una información comprometida con la verdad. La información en los medios de masas debe responder a la necesidad de facilitar claves para comprender la realidad. Responder a los desafíos y los problemas no es posible sin un sistema de información y comunicación verdaderamente democráticos.

Europa debe empezar a confiar en la fuerza de sus movimientos ciudadanos para recuperar pulsión democrática, debe empezar a mirar a su alrededor para entender que es posible y necesario cambiar las reglas del juego y entender que los Medios deben liderar la construcción de nuevos imaginarios más acordes con los tiempos que vivimos, reflexionando que "vivir bien" es un derecho universal, que el "vivir mejor" toma parte de una obsolescencia exigida por el planeta.

\footnotetext{
${ }^{2}$ Realiza diariamente un espacio informativo satírico en la cadena de televisión La Sexta y publica una columna semanal en el diario Público.
} 
Son tiempos donde se hace necesario repensar el mundo, cuando se convierte en una urgencia reivindicar la felicidad, "El derecho a la pereza" como escribió Lafargue, y empezar a ser verdaderamente dueños de nuestro destino. Tiempos de cambio y Europa como la Anaconda tiene que empezar a mudar la piel, está mudando la piel y es necesario para el mundo abandonar la vieja camisa para que sea deglutida por la tierra.

\section{Referencias}

ALFARO, Rosa María. Ciudadan@s de a de veras. Lima: Calandria, 2002. (ed.). De lo estatal a lo público. Medios: ide quién y para quién? Lima: Calandria, 2006.

BELTRÁN, Luis Ramiro: Adios a Aristóteles. 1979. Disponível em: http:// www.alaic.net/portal/revista/r7/art_01.pdf. Acesso em: set.2010.

BRAUNGART, M.; MCDONOUGTS, W. Cradle to cradle. De la cuna a la cuna. Madrid: McGraw Hill, 2005.

CHAPARRO, Manuel. Comunicación y desarrollo. Retos para un nuevo periodismo. Telos, n. 81. Madrid: 2010.

. Cooperación en cultura-comunicación en el mediterráneo. España, Francia e Italia con Marruecos, Túnez y Argelia. Creando Espejos. Madrid: Fundación Alternativas, 2010.

CLOUTIER, Jean. Lére d'emerec ou la comunication audio-scrito-visuelle à L' heure des self-media. Montreal: Les Press de L' Université de Montréal, 1975.

DEBRAY, Regie. El estado seductor. Buenos Aires: Ediciones Mantial, 1993.

ESCOBAR, Arturo. La invención del tecer mundo. Bogotá: Norma, 1996.

Fundación Dag Hammarkjöld. Qué hacer. Upsala: Developement dialogue, 1975.

MARTÍN-BARBERO, J. Pistas para entre-ver medios y mediaciones. Antrophos, n.219. Madrid: 2003.

. De los medios a las mediaciones. Barcelona: G. Gili, 1987. 
PASQUALI, A. Comprender la comunicación. Caracas: Monte Avila, 1973. SERVAES, J. Comunicación para el desarrollo: tres paradigmas, dos modelos. Temas y Problemas de Comunicación, n.10. Rio Cuarto: Universidad Nacional de Río Cuarto, 2002.

SMYTHE, Dallas. La televisión, entre servicio público y negocio. Barcelona: Gustavo Gili, 1983.

Submetido em: 15.07.2011

Aceito em: 25.10.2011 